ISSN: 2277-3754

ISO 9001:2008 Certified

International Journal of Engineering and Innovative Technology (IJEIT)

Volume 10, Issue 1, July 2020

\title{
Production of seed potatoes (Solanum tuberosum L.) during the raining season under tunnels at the Agro-physio-genetic and Plant biotechnologies laboratory of IPR / IFRA in Katibougou, Mali
}

*Abdoulaye SIDIBE ${ }^{1}$, Moussa ABDOULAYE ${ }^{1}$, Hamidou SENOU ${ }^{1}$, Ousmane NIANGALY ${ }^{1}$, Halima MOUSSA

${ }^{1}$ - Teachers - Researchers at the Polytechnic Rural Institute for Training and Applied Research (IPR / IFRA) of Katibougou, Koulikoro, Mali; ${ }^{2}$ - National Directorate of Agriculture, Niamey, Niger.

Abstract: Agriculture represents a huge challenge for the development of Mali. In fact, around $80 \%$ of the population earn their income there. The majority of it is made up of small vulnerable family farms practicing mainly food crops [1]. The potato is the main non-cereal food on earth. World production was estimated in 2013 at more than 376 million tons on 19 million hectares with the use of 32 million tons of seeds. It occupies the fourth food place after corn, rice and wheat, its nutritional and energy qualities are proven. In Mali, the potato is cultivated in the regions of Sikasso, Koulikoro (notably Kati) and Segou. Its main production period is the cool dry season (November to February), but it is also grown to a lesser extent during the winter. The study undertaken under greenhouse wintering at the Agro-physio-genetic and plants Biotechnologies laboratory of the IPR / IFRA of Katibougou, aims to determine if the potato can be cultivated during the wintering and be able to produce seeds. Two of the varieties grown in Mali were used in this study: Claustar and Sahel. The STAT ITCF software was used for data analysis with application of the Newman and Keuls test at the 5\% level for the comparison of treatment means. From the results of this experiment, it appears that the analysis of variance reveals a statistically significant difference in the diameter at the collar between the treatment means. This difference subjected to the Newman and Keuls test at the 5\% threshold indicates two homogeneous groups. Group A is made up of V1 (5.66 at 20 $D A P$ and 6.97 at 30 DAP). Group $B$ is composed of V2 (3.96 to $20 \mathrm{DAP}$ and 4.63 to $30 \mathrm{DAP})$. The analysis of variance reveals a highly significant difference between the treatment means. This difference, subjected to the Newman and Keuls test at the $5 \%$ threshold, signals two homogeneous groups.

Key words: height, weight, plants, potato, tubers, yields.

\section{INTRODUCTION}

Mali is a sahelian country located in the heart of West Africa, with a total area of $1,241,238 \mathrm{~km}^{2}$ [2]; [3]. Its population was estimated in 2013, at $15,968,882$ inhabitants [4] DNSI, 2013), it is subject to significant climatic and natural constraints. The strong demographic growth accentuates the pressure on resources. The contribution of the agriculture sub-sector to Agricultural Development Policy (ADP) is estimated at 46\% (Ministry of Agriculture of Mali, 2012 cited by [5].

Manuscript received: 19 June 2020

Manuscript received in revised form: 15 July 2020

Manuscript accepted: 01 August 2020

Manuscript Available online: 15 August 2020
The general objective of the Agricultural Development Policy (PDA) is "to contribute to making Mali an emerging country where the agricultural sector is the engine of the national economy and guarantor of food sovereignty in logic of sustainable development". One of the specific objectives assigned to the ADP is "to ensure the development of technological innovations through agricultural research and vocational training". Agriculture represents a huge challenge for the development of Mali. In fact, around $80 \%$ of the population earns their income there. The majority of it is made up of small, vulnerable family farms practicing mainly food crops [6]. The practice of industrial, vegetable and fruit crops is also considerable.

The potato is the main non-cereal food on earth. World production was estimated in 2013 at more than 376 million tons on 19 million hectares with the use of 32 million tons of seeds. It occupies the fourth food place after corn, rice and wheat, its nutritional and energetic qualities are proven [7]. Its food value, its protein and carbohydrate supply is higher than that of wheat, rice and corn if we do not compare the content but the average world yield per hectare. It is an excellent source of employment for the most disadvantaged sections of the population: women and young graduates.

The year 2008 has been declared the year of the potato by the FAO, the initiative in particular aims to raise awareness "of the importance of the potato as a food for developing countries, and to promote the research and development of potato-based systems to help achieve the Millennium Development Goals. "

In the Sahelian zone, the crop is still underdeveloped although a significant production potential exists in the dry season, which coincides with low night temperatures favoring tuberization. Major programs are being undertaken to develop the crop there, which should limit the pressure on cereals and minimize the lean season. It is also the most productive food crop, producing more dry matter per hectare than cereals, with $85 \%$ of the dry matter produced by the plant being edible for humans compared to around $50 \%$ for cereals. Its average yield is around 17 tons per hectare in the countries of sub-Saharan Africa, but is between 60 and 90 tons in some developed countries of North America and Western Europe. The potato remains 


\section{ISSN: 2277-3754 \\ ISO 9001:2008 Certified \\ International Journal of Engineering and Innovative Technology (IJEIT) \\ Volume 10, Issue 1, July 2020}

underused in certain Third World countries, notably in sub-Saharan Africa, but overall its consumption is increasing in developing countries, while in developed countries it tends to decrease, tilting more and more towards forms processed (canned, dehydrated or frozen products). Potato starch has given birth to a processing industry with multiple outlets in the agro-food, cosmetic, pharmaceutical and industrial sectors. Given its economic importance, many scientific studies on potatoes and related species, especially in the field of genetics, are carried out by public or private institutions in different countries, coordinated worldwide, among others, by the International Potato Center [8].

In Mali, the potato is cultivated in the regions of Sikasso, Koulikoro (notably Kati) and Segou, its main production period is the cool dry season (from November to February), but it is also cultivated to a lesser extent during wintering. Its culture is perfectly suited to sites where the land is limited but where the workforce is abundant, conditions which characterize a large part of the developing countries. Potato cultivation has taken off since Mali in 1973. The area cultivated in 2014 is estimated at 4,820 hectares for a production of 103,000 tons, i.e. an average yield is 21 tons / ha [9]. The demand for potatoes is constantly increasing, the national market consumes $80 \%$ of the volume and the rest is exported to countries in the sub-regions (Ivory Coast, Burkina Faso, etc.).

According to [10], in West Africa, Mali alone produces more than $70 \%$ of the production of the five producing countries (Mali: 114,478 tons; Niger: 18,000 tons; Guinea: 11,876 tons; Senegal: 10,000 tons; Burkina Faso: 1,700 tons). Today, this culture is integrated into the production systems of peasants in the area because it is very profitable. The demand for potatoes has always increased, taking into account the increase of the population and the eating habits both at national and sub-regional level. This strong demographic growth accentuates the pressure on resources thus widening a gap between supply and demand [11]. In 2014, Mali imported almost 7,740 tons of potatoes for consumption [12]. The potato is interesting for various reasons. From an agronomic point of view, its cultivation is easy and, in the cool dry season or at altitude, its yield potential is significant (30 tons / ha or even more). From a nutritional point of view, it ranks among the most nutritious root or tuber plants. It is interesting to note that the potato is the plant that produces the largest amount of food per day of land use; it therefore requires less work and less water.

Finally, and this is undoubtedly one of the most determining factors, it is highly appreciated by the populations. Indeed, if it is sold at a price within the reach of the purchasing power of the population, demand is high. It is a cash crop for farmers who obtain satisfactory yields. In addition, given the increase in the consumption of the tuber and the increase in the population, demand in Mali in 1992 was greater than the supply of 109,000 tons [13].
According to [14], potatoes have become an important staple in most poor regions of the world. The potato is a vegetable considered to be a starchy food because of its richness in starches. While it is a good source of complex carbohydrates, it also offers good levels of vitamin $\mathrm{C}$ and mineral salts. To take advantage of its nutritional advantages, it is better to opt for a cooking method without fat, and consume it with your skin. Cooking is also necessary for the proper assimilation of its starch. However, if the potato culture is among the most promising in Africa, its development remains hampered by various constraints, among which we can say:

- Limited access to quality seeds;

- A lack of technical knowledge among promoters;

- No-existence or poorly performing storage infrastructures;

- Insufficiency of robust varieties well adapted to the different growing conditions;

- Difficult access to credit [15].

\section{A. Overview on the trial site: IPR / IFRA of Katibougou}

- The geographic coordinates of the site of the trial are as follows: $12^{\circ} 56$ north elevation; $7^{\circ} 32$ west longitude, $326 \mathrm{~m}$ altitude. It is located on the $900 \mathrm{~mm}$ isohyet. Its domain which extends on the left bank of the Niger river.

- The relief is characterized by the presence of hills and plateaus overhanging to the north-west the cultivable areas and dominance towards the south-west of the lowlands occupied by the plains which are periodically flooded by the floods of the river in certain places.

- The Sudano-Sahelian climate is characterized by a dry season from October to the end of May or June (7 to 8 months) and a rainy season from June to the beginning of October (4 to 5 months).

- The soils of Katibougou are diverse. The main types of soil encountered are shallow amphigley hydromorphic soils with a sandy-silty texture of greyish-brown appearance with a large amplitude ground flapping. They get waterlogged in the rainy season.

- The vegetation is characterized by a shrubby or wooded savannah. This formation is accompanied by a mixture of annual grasses [16].

- The laboratory has four acclimatization tunnels of 10,000 plants each (Figure 1) and experimental plots of around 6 ha.

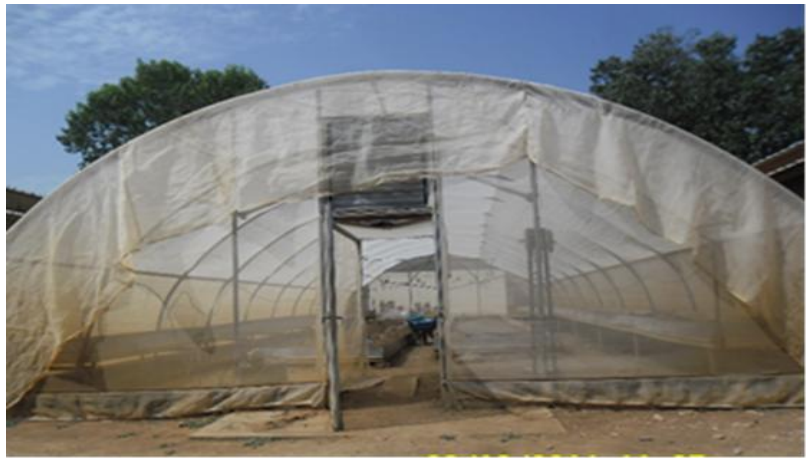

Fig 1: Greenhouse for acclimatization of vitro plants at IPR / IFRA (Harouna, 2014). 
ISSN: 2277-3754

ISO 9001:2008 Certified

International Journal of Engineering and Innovative Technology (IJEIT)

Volume 10, Issue 1, July 2020

\section{B. Potato (Solanum tuberosum L.)}

The potato (Solanum tuberosum L.) is native to the Andes in South America, on the borders of Bolivia and Peru, high altitude tropical regions where the days are short. [17], it was quickly distributed around the world and in 2015 was cultivated in several countries in practically all inhabited latitudes.

The potato is an edible tuber produced by the species Solanum tuberosum, belonging to the nightshade family. The term also refers to the plant itself. The potato is a deciduous, tuberous herb (it loses its leaves and aerial stems in the cold season). The potato is a successful plant in most soils, but prefers light, slightly acidic soils [18].The flowering of the plant is weak, but present. The flowers are grouped in a cyme inflorescence, always located at the end of a stem and carried by an inflorescent stem, improperly called - Peduncle (Figure 2).

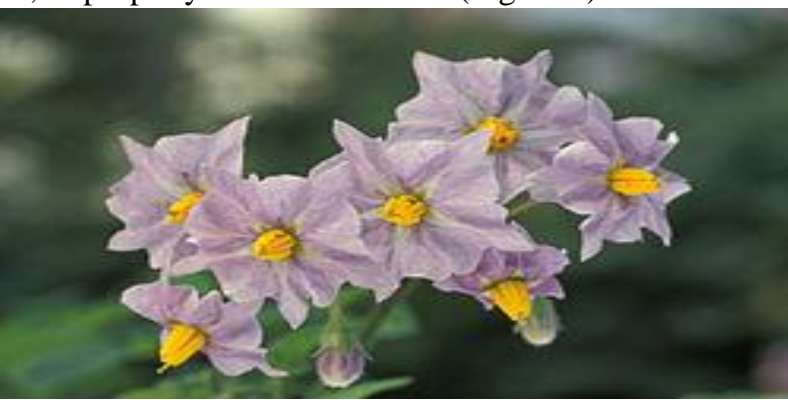

(a)

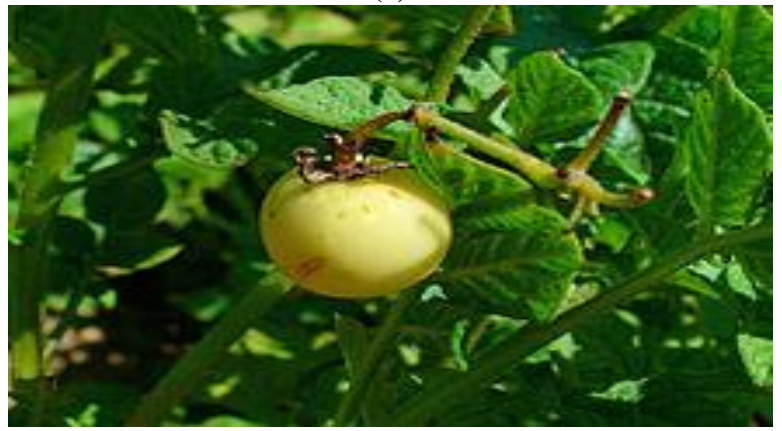

(b)

Fig 2:a. Inflorescence and flowers of potato; b. Potato fruit (Harouna, 2014).

The fruit of the potato is a berry that looks like a small tomato. It is not edible. [19]. The flattened seeds, oval or kidney shaped and white, yellow or yellowish brown in color13, are small; there are 1,000 to 1,500 seeds per gram. They are albuminated and the embryo is rolled up (Figure 3).The root system is fascinated and very branched; it tends to extend superficially but can sink down to $0.8 \mathrm{~m}$ deep. It consists of adventitious roots which appear at the base of the tuber buds or on the nodes of buried stems [20]. The shape of the tuber varies from round, to oval, long, etc. Seen (Figure 3 A) and multiplication is done through the shoots on the tuber (Figure 3 B).

The potato is a very hardy plant which withstands cold (freezing at $2{ }^{\circ} \mathrm{C}$ ) and heat relatively well. Excessive temperature does not bother him unless it is accompanied by dryness. The optimum is between 15 to $25^{\circ} \mathrm{C}$.
The rainfall regime greatly influences the yield and quality of the tubers. Its water needs are around 500 to 800 $\mathrm{mm}$ depending on the different growing areas. The potato requires deep, healthy soils that are always fresh, rich and well drained. It grows well on sandy humus soils and prefers soils with a low acid pH of 6 to 6.5.

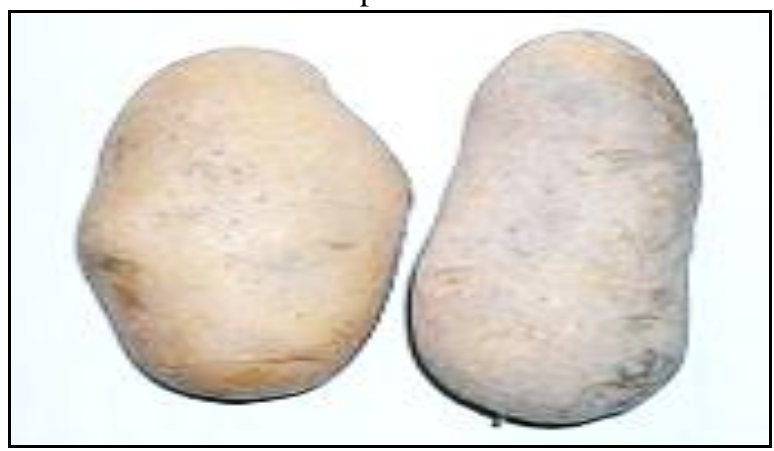

(a)

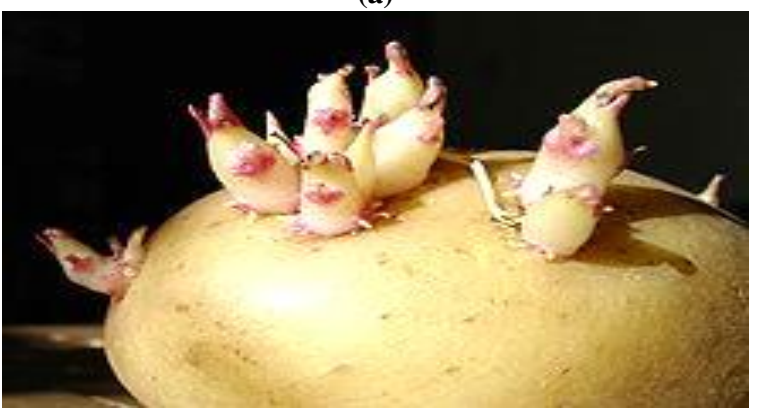

(b)

Fig 3: a- Potato tubers and b- Sprouts developed on the potato tuber (Sidibe, 2017).

\section{Potato seed production in Mali}

Given the increase in potatoes in Mali, storage problems, the price and quality of imported seeds, the quality and small quantity of seeds produced locally, a seed production scheme in Mali has been drawn up from the Plants Biotechnology Laboratory at IPR / IFRA of Katibougou. In addition to this strain production in the laboratory, local production of potato seeds is carried out among farmers.

\section{Seeds produced locally}

Produced from certified seeds imported from Europe, generally of classes B or A, it is of the following types:

- "chicoroni": small sizes sorted in the previous cold season. They are used for primary cultivation in the shallows and are planted whole;

-"fassamani": these are the deviations from the previous cold season but kept for seven to eight months;

-"tikadan", medium-sized, the tubers are split before being planted [21].

\section{E. Micro propagation in the laboratory}

In vitro culture or micro propagation is the conforming mode of multiplication, which involves starting from a disease-free tuber. The starting tubers are selected strictly according to their origin (preferably in a varietal collection or a high quality plot), the visual aspect (conformity to the varietal type) and after different analyzes in the Laboratory to check the absence of attacks by viruses, bacteria, fungi, 


\section{WEIT}

ISSN: 2277-3754

\section{ISO 9001:2008 Certified}

International Journal of Engineering and Innovative Technology (IJEIT)

Volume 10, Issue 1, July 2020

etc. The tuber is then put to germinate then, after disinfection; we take either a germ bud or apex, or a meristem which we place in a tube containing a suitable nutritive medium. The plant placed in ideal conditions: culture medium containing all the elements necessary for its growth (macro elements and micro elements, vitamins, phytohormones, sugar), temperature of $20-24{ }^{\circ} \mathrm{C}$, lighting (intensity and photoperiod) controlled in rooms airconditioned develop very quickly.

- From in vitro plants: After rooting, the plants are taken out of the sterile laboratory conditions to be planted in an organic substrate. Acclimatization takes place in a greenhouse, in soil, to "heat" and humidity. After 2 to three (03) weeks, the rooted plants are transferred to a greenhouse or tunnel to produce mini tubers (diameter 8 to $28 \mathrm{~mm}$ ) called G0: starting material;

- From micro-tubers: These are small tubers (3 to 8 $\mathrm{mm}$ ), which are obtained by placing the plants in conditions inducing tuberization: modification of the culture medium, reduction of lighting (darkness);

- Production in a tunnel: Acclimatized vitro plants or pre-germinated micro-tubers are planted in a tunnel with 'insect-proof', where they develop. One can obtain from these materials mini tubers or tubers of 8 to $28 \mathrm{~mm}$ in diameter (G0);

- Field production: G0 tubers from tunnels are distributed among specialized producers who produce the first three years of field multiplication: G1, G2 and G3. These high-quality plants, with more stringent standards than the super-Elite, must be subject to many precautions: protective isolation, limitation of passages in the plot, gentle harvesting [22].

\section{A. Material}

\section{MATERIALS AND METHODS}

\section{Site of the trial}

The test was installed in the laboratory tunnel on a table filled with a mixture of potting soil and wood stain (not proportionate) used as soil for the support of plants. A table $19.45 \mathrm{~m}$ long and $0.80 \mathrm{~m}$ wide.

\section{Plant material}

The plant material is composed of two varieties of generation three potatoes (G3) which are the Claustar and the Sahel. Agricultural equipment and products used

A number of materials were used during our work, namely: wheelbarrow, shovel, precision balance, sprayer for phytosanitary treatments, potting soil, steam sterilizer for disinfection of potting soil, firewood, carbofuran (nematicidal insecticide), ridomil (fungicide), lambda (insecticide) formula 15-15-15, calibrator, caliper, graduated ruler, measuring tape.

\section{B. Method}

\section{Factors studied}

In the test only one factor is studied: the variety; it is the Claustar variety (V1) and the Sahel variety (V2). The treatments are repeated six times each, so the test is made up of six blocks.

\section{Treatments}

All treatments are without distinction. They have the same planting densities, the same doses of fertilizer and products for phytosanitary treatments.

\section{Experimental apparatus}

The device is total randomization with 6 repetitions. The test is made up of twelve elementary treatments or plots $1.4 \mathrm{~m}$ long and $0.80 \mathrm{~m}$ wide. Each plot has 5 lines spaced $30 \mathrm{~cm}$ apart and 10 pockets / line spaced $20 \mathrm{~cm}$ apart.

\section{Plot dimensions}

- Treatments: $1.4 \mathrm{~m}$ x $0.80 \mathrm{~m}$, or $1.12 \mathrm{~m}^{2}$;

- Blocks: $1.12 \mathrm{~m} 2$ x 2 with aisles of $0.20 \mathrm{~m}$;

- Total area of the test: $19.45 \mathrm{mx} 1.80 \mathrm{~m}$ or $16.53 \mathrm{~m}^{2}$.

The potting soil, for mounding the potato plants (Figure

4 ) on the table, is sterilized over a wood fire (Figure 5).

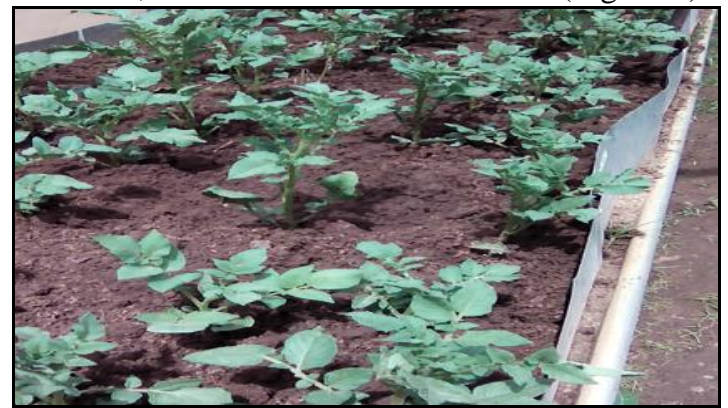

(a)

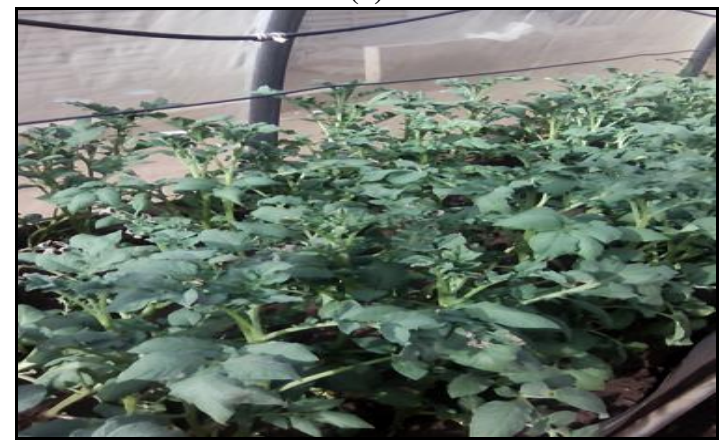

(b)

Fig 4: View of the potato plants a) at the 27th and b) at the 43rd day after planting (Moussa, 2014).

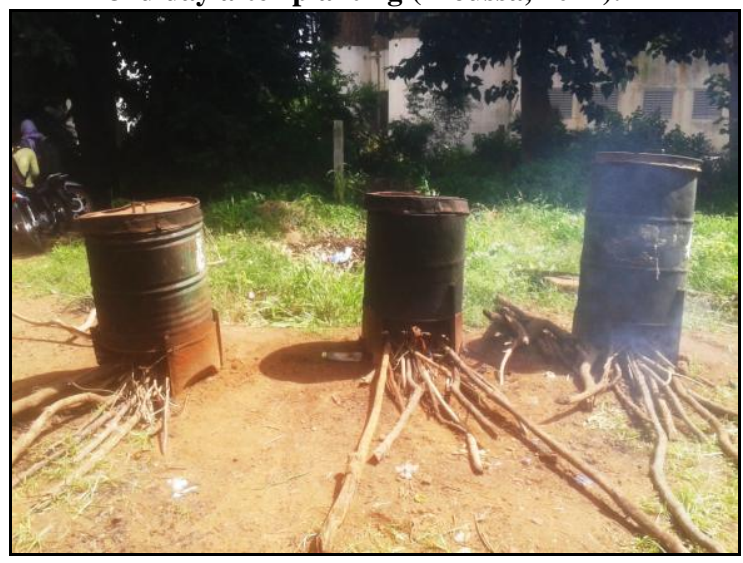

Fig 5: Sterilization of hilling soil over a wood fire (Sidibé, 2017). 
ISSN: 2277-3754

\section{ISO 9001:2008 Certified}

International Journal of Engineering and Innovative Technology (IJEIT)

Volume 10, Issue 1, July 2020

\section{Statistical data analysis method}

Statistical analyzes were carried out using the STATITCF software, with application of the Newman and Keuls test at the 5\% threshold for the comparison of treatment and sub-treatment means.

\section{A. Percentage of lifting}

\section{RESULTS AND DISCUSSION}

The analysis of variance does not indicate a statistically significant difference between the treatment means (Figure 6). However, the arithmetic values indicate that V1 (Claustar) had the highest rate of emergence on the 14th and 21 st days, namely $56.6 \%$ and $62.66 \%$ respectively. On the other hand, V2 (Sahel) was more favorable for emergence with a percentage of $38.33 \%$ on the 7 th Day after Planting (DAP).

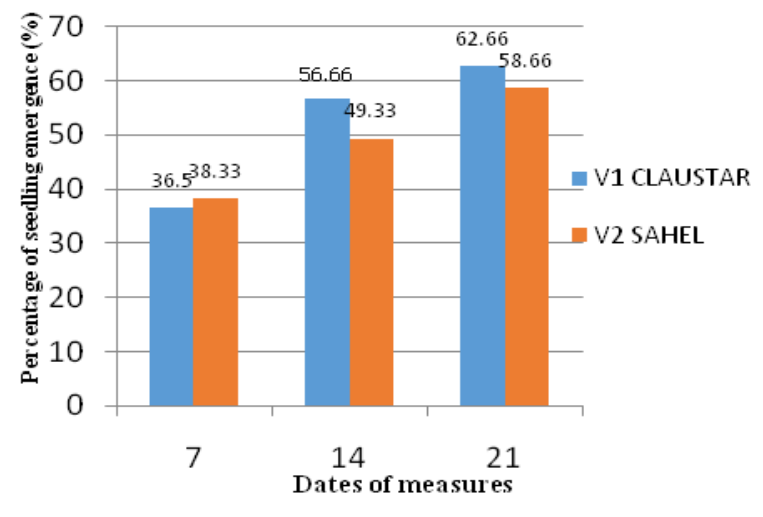

Fig 6: Percentage of seedling emergence

\section{B. Number of stems per pocket}

The analysis of variance did not show a statistically significant difference between the treatment means. However, the arithmetic values indicated that V1 the Claustar variety has the highest number of stems compared to V2 the Sahel variety (Figure 7).

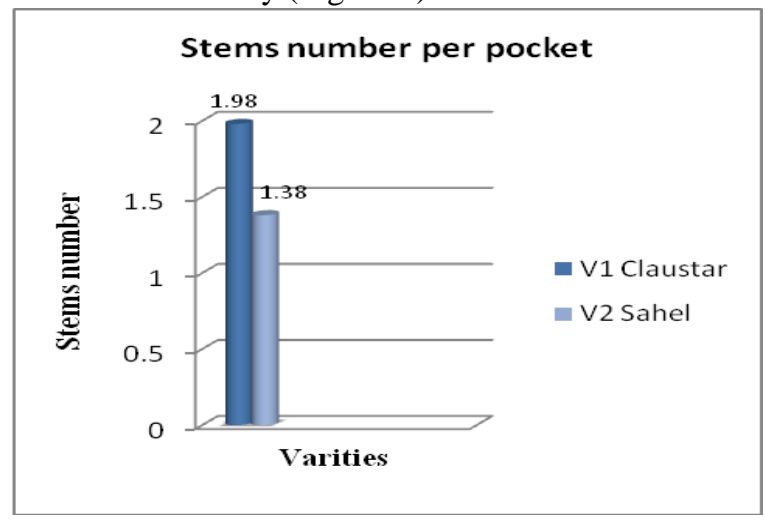

Fig 7: Number of stems per pocket.

\section{Average height per plant (cm)}

The analysis of variance does not show a statistically significant difference between the treatment means. The arithmetic values indicate that the Sahel has a lower height compared to the Claustar. This physiognomy is expressed on the Figure 8 .

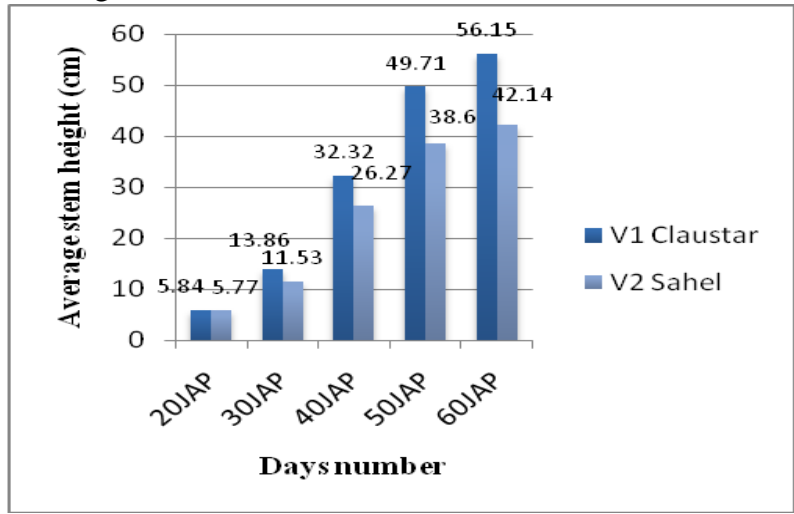

Fig 8: Height of the stems (in cm).

\section{Average diameter at the collar of the plants (cm).}

The analysis of variance reveals a statistically significant difference between the treatment means. This difference subjected to the Newman and Keuls test at the $5 \%$ threshold indicates two homogeneous groups. Group A is made up of Claustar: 5.66 to $20 \mathrm{JAP}$ and 6.97 to 30 DAP. Group B is made up of the Sahel: 3.96 to 20 DAP and 4.63 to 30 DAP (Figure 9).

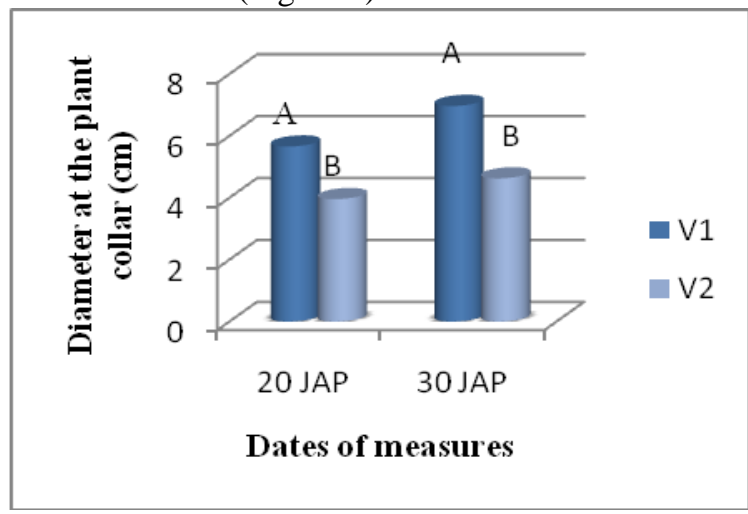

Fig 9: Diameter at the collar of the plants (in $\mathrm{cm}$ ).

\section{E. Average number of leaves per plant}

The analysis of variance does not show a statistically significant difference between the treatment means. The arithmetic values indicate that the Claustar gave more leaves than the Sahel. This physiognomy is expressed in Figure 10.

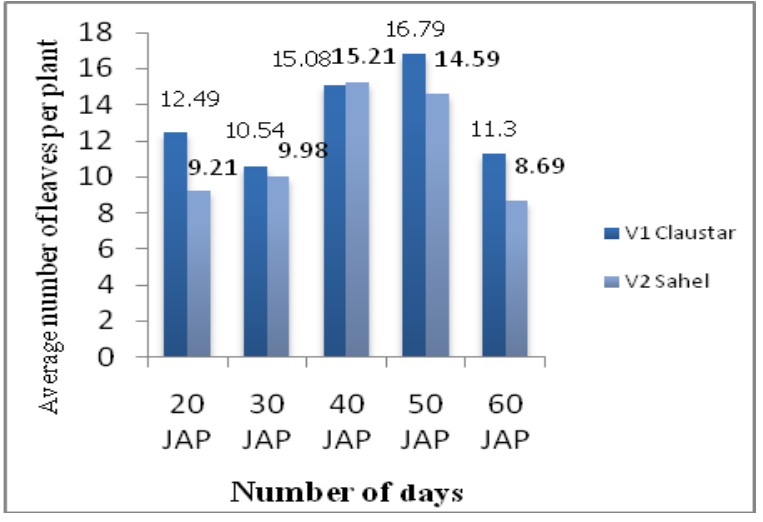

Fig 10: Average number of leaves per plant 
ISSN: 2277-3754

\section{ISO 9001:2008 Certified \\ International Journal of Engineering and Innovative Technology (IJEIT) \\ Volume 10, Issue 1, July 2020}

\section{F. Average number of branches per plant}

The analysis of variance does not show a statistically significant difference between the treatment means. But the arithmetic values (Figure 12) show that the Claustar gave more branches than the Sahel on the 40th day and the Sahel gave more branches on the 50th and 60th DAP. This physiognomy is expressed through the Figure 11.

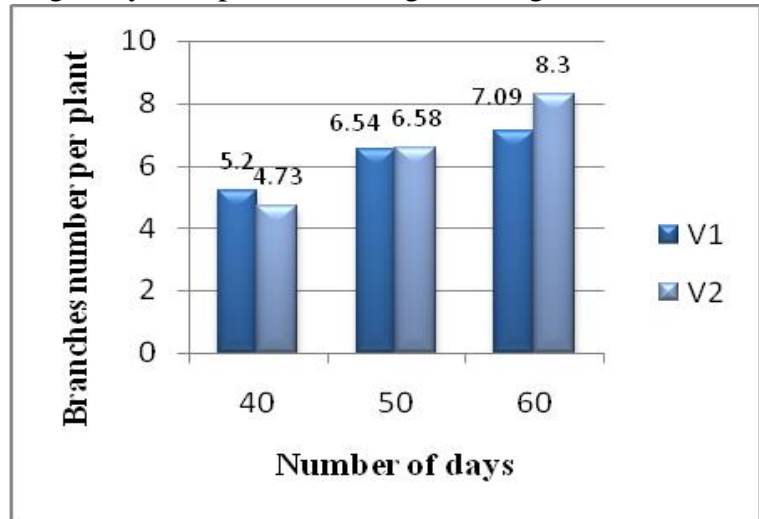

Fig 11: Branches number per plant.

\section{G. Number of tubers per plant}

The analysis of variance reveals a highly significant difference between the treatment means (Table 1). This difference subjected to the Newman and Keuls test at the $5 \%$ threshold indicates two homogeneous groups. Group A is made up of Claustar. Group B is made up of the Sahel (Figure 12).

Table 1: Analysis of variance of the number of tubers per plant

\begin{tabular}{|l|c|c|c|}
\hline & $\begin{array}{l}\text { Squares } \\
\text { Sum of } \\
\text { deviations }\end{array}$ & $\begin{array}{l}\text { Degree } \\
\text { of } \\
\text { Liberty }\end{array}$ & $\begin{array}{l}\text { Medium } \\
\text { squares }\end{array}$ \\
\hline Total variables & 3.90 & 1 & 0.35 \\
\hline $\begin{array}{l}\text { Variable } \\
\text { Factor 1 }\end{array}$ & 0.54 & 1 & 0.54 \\
\hline $\begin{array}{l}\text { Variable } \\
\text { Blocks }\end{array}$ & 3.29 & 5 & 0.66 \\
\hline $\begin{array}{l}\text { Residual } \\
\text { variable 1 }\end{array}$ & 0.08 & 5 & 0.02 \\
\hline
\end{tabular}

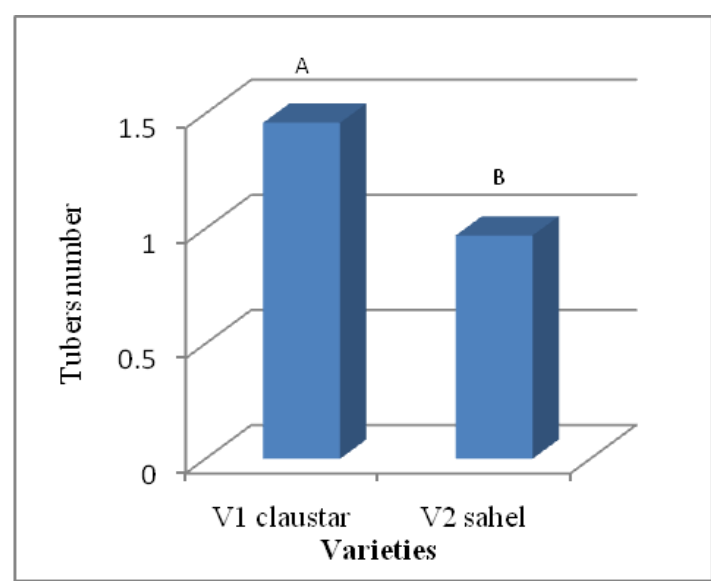

Fig 12: Number of tubers per plant at the harvest.

\section{H. Average weight of a tuber (g)}

The analysis of variance does not show a statistically significant difference between the treatment means. But the arithmetic values show that the tubers of the Sahel weigh heavier than those of the Claustar. The difference is expressed in Figure 13.

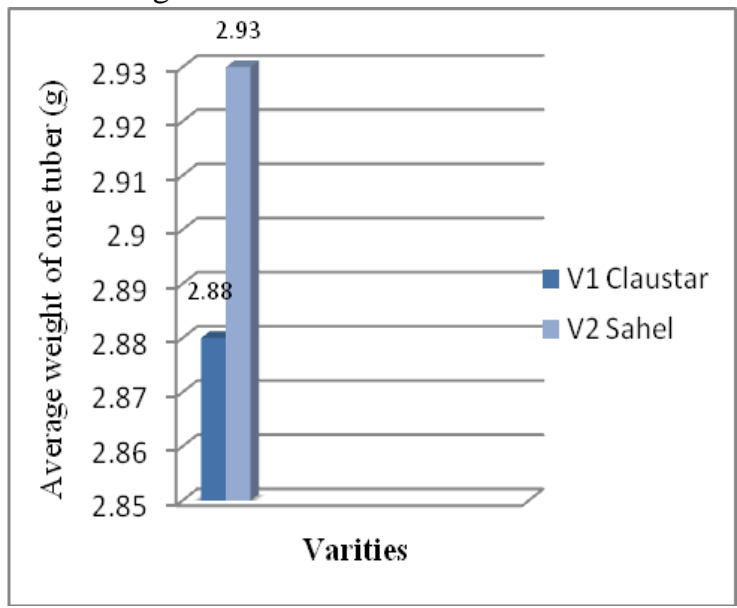

Fig 13: Average weight of a tuber (g).

\section{Average caliber of a tuber ( $\mathrm{mm})$}

The Figure 14 shows an arithmetic difference between the treatments compared to the different calibers. Concerning the caliber A (diameter less than or equal to 28 $\mathrm{mm}$ ) the treatment of Claustar gave more tubers compared to the treatment of the Sahel, concerning the caliber B (diameter greater than $28 \mathrm{~mm}$ and less than or equal to 35 $\mathrm{mm})$; the Sahel treatment gave more tubers compared to the Claustar treatment and concerning size $\mathrm{C}$ (diameter greater than $35 \mathrm{~mm}$ ) the Claustar treatment did not give tubers; while, the Sahel treatment gave three (03).

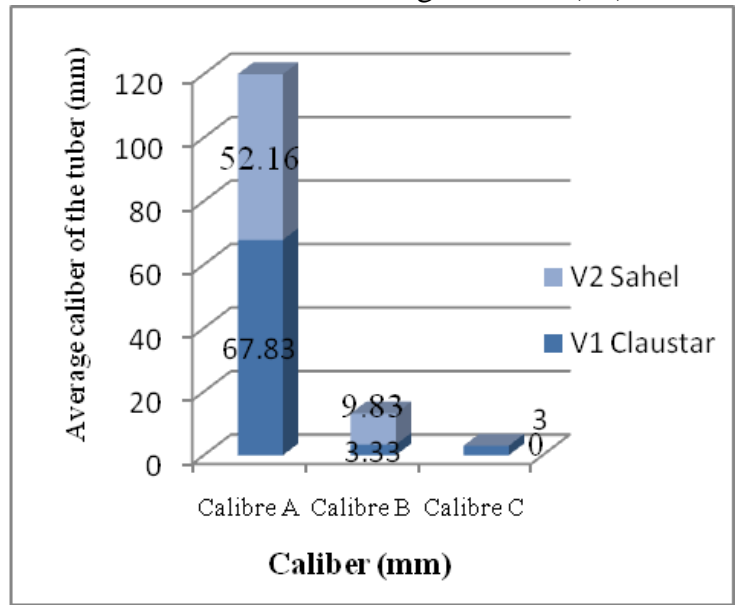

Fig 14: Average caliber of a tuber (mm).

\section{J. Average weight of a tuber per size, in grams}

Figure 15 shows an arithmetic difference between the treatments compared to the different calibers; at the level of caliber B (diameter greater than $28 \mathrm{~mm}$ and less than or equal to $35 \mathrm{~mm}$ ) and of caliber $\mathrm{C}$ (diameter greater than 35 $\mathrm{mm})$, where the Sahel exceeds the Claustar. The tubers of 


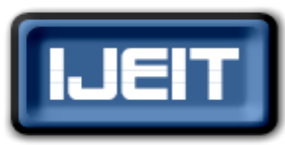

\section{ISSN: 2277-3754 \\ ISO 9001:2008 Certified \\ International Journal of Engineering and Innovative Technology (IJEIT) \\ Volume 10, Issue 1, July 2020}

the two varieties, Claustar and Sahel, are visible on the Figure 16.

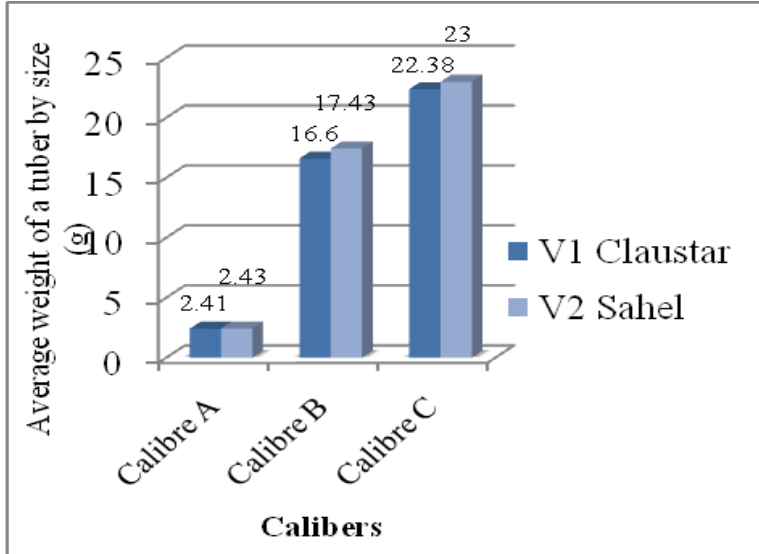

Fig 15: Average weight of a tuber by size (in g).

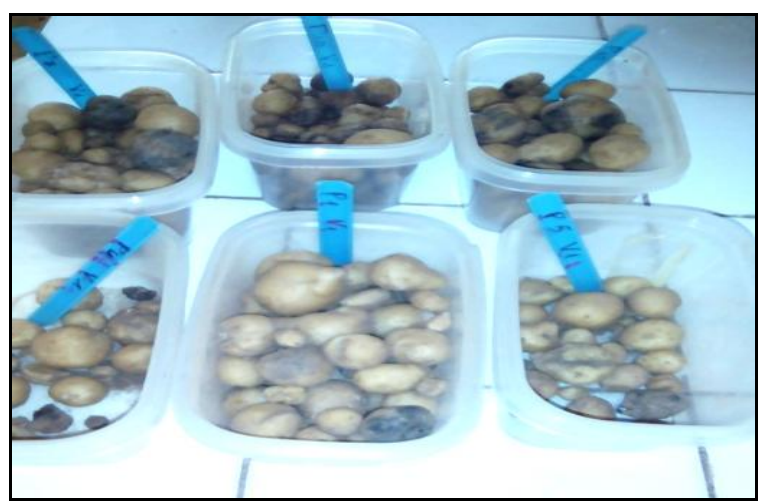

(a)

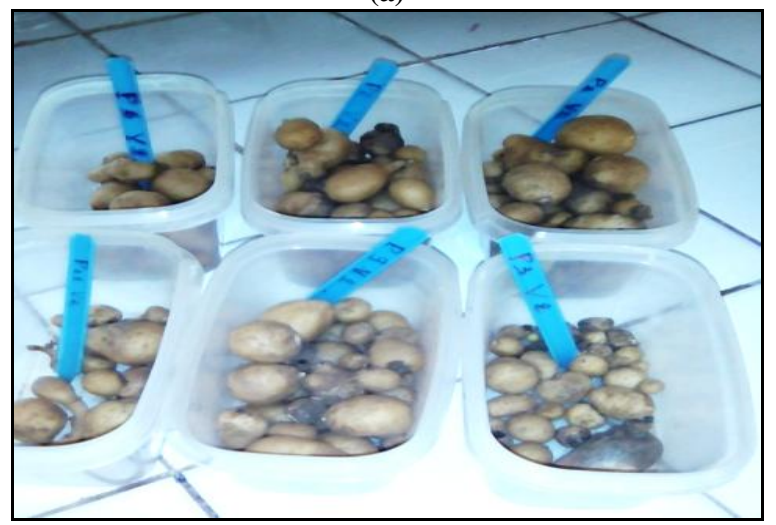

(b)

Fig 16: Tubers of the two varieties harvested: a) Claustar and b) Sahel.

\section{CONCLUSION}

At the end of this study on the production of seed potatoes overwintering in tunnels at IPR / IFRA, it appears that there was no statistically significant difference between the treatment averages. However, the arithmetic values indicate that the Claustar has the highest rate of emergence on the 14th and 21 st days, namely $56.6 \%$ and $62.66 \%$ respectively. These results confirm those of [23] on different varieties of potato. On the other hand, the Sahel variety was more favorable for emergence with a percentage of $38.33 \%$. Between the two varieties, the analysis of variance does not show a statistically significant difference between the treatment means. The arithmetic values indicate that the Sahel variety has a significant height compared to the Claustar variety. The analysis of variance reveals a statistically significant difference in the diameter of the collar between the treatment means; which corroborates with the results obtained by [24] and [25]. This difference subjected to the Newman and Keuls test at the 5\% threshold indicates two homogeneous groups. Group A is made up of Claustar (5.66 to 20 days after planting and 6.97 to 30 days after planting). Group B is made up of Sahel (3.96 to 20 DAP and 4.63 to 30 DAP).An arithmetic difference was noted between the treatments compared to the different calibers; at the level of caliber B (diameter greater than $28 \mathrm{~mm}$ and less than or equal to $35 \mathrm{~mm}$ ) and of caliber $\mathrm{C}$ (diameter greater than $35 \mathrm{~mm}$ ), where the Sahel exceeds the Claustar.

\section{REFERENCES}

[1] H. Ladan, 'Micro propagation of two varieties of papaya (Carica papaya L.) at IPR / IFRA Katibougou, Mali', 52 pages, 2014.

[2] PDA, " Agricultural Development Policy of Mali, Republic of Mali ', 40 pages. 2013.

[3] PCDA, Competitiveness and Agricultural Diversification Program. Report on the potato season, 25 pages, 2013.

[4] DNSI, 'Annual report of the National Statistics Division', 25 pages, 2013.

[5] M. Yaye, "Effects of mineral fertilization and dolomite on sorghum (Sorghum bicolor) in the Sudanian zone of Mali". End of cycle thesis, IPR / IFRA Katibougou, 96 p, 2016.

[6] H. Ladan, 'Micro propagation of two varieties of papaya (Carica papaya L.) at the IPR / IFRA of Katibougou, Mali', 52 pages, 2014.

[7] FAOSTAT and CPS / SDR, Review of agricultural and food policies in Mali '. 2 p., 2013. http: //faostat.fao.org accessed March 10, 2017.

[8] P. Le Corre, J. M. Gravoueille, M. Martin, 'The culture of the conservation potato' - ITCF / ITPT, 64 p., 1995.

[9] FAOSTAT and CPS / SDR, Review of agricultural and food policies in Mali '. http: //faostat.fao.org accessed March 10, 2017, 2013.

[10] FAOSTAT, 2016. URL address: http://faostat3.fao.org/statistic, page consulted on 03/19/2017.

[11] Ministry of Agriculture of Mali, 'Annual Report of the Agricultural Campaign, 12 - 14 pages, 2012.

[12] GIPT-Mali, Groupement de la Interprofession de la Potato au Mali. Report on the potato season, 9 pages, 2014.

[13] IER, Online: 'www.ier.gouv.ml/cultures' Cultures irrigées ', page consulted on September 19, 2016, 1992.

[14] FAO, URL: http://faostat3.fao.org/statistic, page consulted September 19, 2016, 2016. 
ISSN: 2277-3754

ISO 9001:2008 Certified

International Journal of Engineering and Innovative Technology (IJEIT)

Volume 10, Issue 1, July 2020

[15] B. Vanderhofstadt, B. Jouan, Technical guide to potato cultivation in West Africa ', 82 p, 2009.

[16] G. Holfelder, "Farm Extension Study Report", 85 p, 1978.

[17] H. Romain, 'Agriculture in tropical Africa', 1634 p, 2001.

[18] P. Rousselle, Y. Robert, J. C. Crosnier, 'The potato' INRA, 607 p, 1996.

[19] Technical information bulletin, 'Bulletins d'information technique', 1987 - The potato - CIP, 136 p, 1987.

[20] P. Rousselle, Y. Robert, J. C. Crosnier, 'The potato' - INRA, 607 p, 1996.

[21] O. Diabaté, M. Kéïta, 'Production of mini-tubers G0 of potato (Solanum tuberosum L.) under tunnel at the Plant biotechnology laboratory of L'IPR / IFRA Katibougou', 34 pages, 2016.

[22] O. Diabaté, M. Kéïta, 'Production of mini-tubers G0 of potato (Solanum tuberosum L.) under tunnel at the Laboratory of plant biotechnologies of L'IPR / IFRA of Katibougou', 34 pages, 2016.

[23] A. Ohayitt, 'Comparative study of 13 varieties of potato (Solanum tuberosumL.) In the Sudano Sahelian zone of Katibougou', Mémoire de DEA, 70 p, 2016.

[24] B. Konaté, 2015 'Micro propagation of two varieties of potato (Solanum tuberosumL.) At the Agro-physio-genetics and plant biotechnology laboratory at the IPR / IFRA in Katibougou', 40 pages, 2015 .

[25] Z. Issoufou, 'Effects of 5 planting densities on the production of $\mathrm{G} 3$ seeds of two (02) varieties of potato (Sahel and Claustar)', 54 pages, 2016. 